Article

\title{
Deformation-Induced Crystallization Behavior of Isotactic Polypropylene Sheets Containing a $\beta$-Nucleating Agent under Solid-State Stretching
}

\author{
Huajian Ji®, Xulin Zhou, Xin Chen, Haili Zhao, Yu Wang, Huihao Zhu, Yulu Ma \\ and Linsheng Xie * \\ School of Mechanical and Power Engineering, East China University of Science and Technology, \\ Shanghai 200237, China; shxiaoji@163.com (H.J.); 15527377408@163.com (X.Z.); \\ chenxin198905@aliyun.com (X.C.); zhl419wsm@163.com (H.Z.); apirl.1992@outlook.com (Y.W.); \\ zhhxhhy1994@126.com (H.Z.); myl@ecust.edu.cn (Y.M.) \\ * Correspondence: lsxie@ecust.edu.cn; Tel.: +86-021-64252363
}

Received: 10 April 2020; Accepted: 28 May 2020; Published: 30 May 2020

check for updates

\begin{abstract}
The deformation-induced crystallization of an isotactic polypropylene (iPP) sheet containing a $\beta$-nucleating agent was evaluated. The phase transformation of the $\beta$-modifications was investigated and the crystal morphology was observed at room temperature after stretching at different temperatures. The results showed that the crystallinity increased after solid-state stretching. When the stretching temperature was below the initial crystallization temperature, stretching deformation promoted the orientation of amorphous molecular chains. When the deformation temperature exceeded the crystallization temperature, part of the $\beta$-modifications underwent a phase transformation process and was stretched into a shish-kebab structure. However, once the stretching temperature was close to the melting point, the $\beta$-modifications melted and recrystallized, and the shish-kebab structure underwent stress relaxation due to poor thermal stability, transforming into $\alpha$-modifications. It was revealed that the crystal phase transformation mechanism of the $\beta$-modifications was based on the orientation of the molecular chains between the adjacent lamellae. In addition, the shish-kebab cylindrite structure played an important role in modifying the tensile and impact properties of the iPP sheet. The tensile and impact strengths increased by as much as $34 \%$ and $126 \%$, respectively.
\end{abstract}

Keywords: solid-state stretching; $\beta$-modification iPP sheet; phase transformation; cylindrites

\section{Introduction}

As a general plastic, isotactic polypropylene (iPP) is mainly used in films, packaging, and the automotive industry [1-4]. iPP has four crystalline structures: $\alpha$-modifications, $\beta$-modifications, $\gamma$-modifications, and smectic modifications [5-7]. $\alpha$-modification iPP has excellent tensile strength but poor toughness [8], while $\beta$-modification iPP has better thermal properties and toughness [9]. Thus far, many researchers have studied the crystallization behavior of iPP containing a $\beta$-nucleating agent, and reported that the growth rate of the $\beta$-modification was $70 \%$ higher than that of the $\alpha$-modification [10-13]. Varga and Menyhárd [14,15] proved that the nucleating agent could affect the molecular structure of iPP, and revealed that multiple $\beta$-modification morphologies existed in iPP crystalline modifications. $\gamma$-modification iPP is induced by the application of high pressure during the crystallization process [16]. Lezak et al. [17] studied the morphology and deformation behavior of iPP homopolymer containing $\gamma$-modifications obtained from isothermal crystallization at a high pressure of $200 \mathrm{MPa}$. Mostly, $\gamma$-modification iPP exists under high pressure-the higher the pressure, the larger the fraction of $\gamma$-modifications [18]. 
Polymer processing endows polymer products with multiple microstructures, owing to the chain orientation and multiphases. These microstructures regulate the macroscopic mechanical performance, which eventually affects the service life of the products. $\beta$-modification iPP exhibits capability of transforming the $\beta$-phase into another crystalline phase $[19,20]$. Li et al. [21] observed that the $\beta-\alpha$ transformation in the neck region and the crystallinity in their samples were nearly constant for engineering strains below 100\%, which then slowly decreased for larger strains. Ruiying Bao et al. [22] studied the deformation-induced structure evolution of iPP. They suggested that $\beta-\alpha$ transformation was induced by intra-lamellar slips. As the deformation temperature increased, the $\beta$-modifications were reoriented by stretching. Riekel and Karger-Kocsis [23] also revealed that $\beta$-modifications were transformed into oriented $\alpha$-modifications under deformation-induced processing. Shi et al. [19] also claimed that $\beta$-modifications were transformed into a smectic crystal when the stretching temperature was below $80^{\circ} \mathrm{C}$; however, they transformed into stable $\alpha$-modifications at higher temperatures. Lezak et al. [24] studied the evolution of the lamellar structure of $\beta$-modification iPP. The authors suggested that inter-lamellar slips promoted the fragmentation of lamellae under higher strain, and rotation of the unconstrained fragmentation crystallites occurred along the stretching direction. However, there is still some uncertainty in the true process of $\beta$-phase transformation due to insufficient experimental evidence [25].

The stretching deformation range of the sheet is much lower than that of the film. At present, there are more studies on iPP films subjected to high deformations, but fewer studies on iPP sheets subjected to low deformations. Updated synchrotron radiation X-ray diffraction is equipped to study the deformation-induced crystallization behavior in $\beta$-modification iPP [26,27]. Sheng et al. [3] researched the mechanical properties of iPP sheets by adding a nucleating agent, and suggested that the impact strength was enhanced, but that the tensile strength was not significantly improved.

In this work, the $\beta$-nucleating agent TMB- 5 was used to prepare a $\beta$-modification iPP sheet. The evolution of the microstructure of the iPP sheet at different stretching temperatures was investigated. In our previous work [28], we studied the evolution process of the $\alpha$-modification lamellae phase transition of pure iPP during solid-state stretching. This work elucidated the temperature-related $\beta$-modification lamellae structural transformation and deformation-induced mechanism of $\beta$-modification iPP. It also clarifies the regulating mechanism of the microstructure on the mechanical properties. Additionally, it is an effective method for preparing both excellent tensile and impact properties.

\section{Materials and Methods}

\subsection{Materials and Sample Preparation}

iPP (1100N; $\mathrm{M}_{\mathrm{n}} 46,000 \mathrm{~kg} \cdot \mathrm{mol}^{-1}$ and $\mathrm{M}_{\mathrm{w}} 317,000 \mathrm{~kg} \cdot \mathrm{mol}^{-1}$ ) with a melt flow rate (MFR) of $12.8 \mathrm{~g} / 10 \mathrm{~min}\left(230^{\circ} \mathrm{C} / 2.16 \mathrm{~kg}\right)$ was supported by Shenhua Group Corporation Ltd., Yinchuan, China. $\mathrm{T}_{\mathrm{m}}=165^{\circ} \mathrm{C}$. The $\beta$-nucleating agent TMB-5 (N,N'-dicyclohexyl-2,6-naphthalenedicarboxamide) was provided by Shanxi Chemical Industry Research Institute, Xian, China.

iPP and TMB-5 were mixed using a twin-rotor continuous mixing extruder (Laboratory homemade). The barrel temperature was $200{ }^{\circ} \mathrm{C}$. The content of TMB- 5 was $0.02 \mathrm{wt} \%$. The pelletized iPP containing the $\beta$-nucleating agent was injection-molded into an iPP sheet sample $(180 \mathrm{~mm}$ in length, $15 \mathrm{~mm}$ in width, and $3.5 \mathrm{~mm}$ in thickness) using an injection-molding machine (COSMOS 80, Ge Lan Manufacture Co., Ltd., Wuxi, China). The injection temperature was $200^{\circ} \mathrm{C}$. Samples were stretched using the following experimental protocol: (1) The sheets were clamped by a tensile testing machine with a high-temperature test chamber; (2) the sample was heated from room temperature to testing temperature (i.e., $110{ }^{\circ} \mathrm{C}, 120^{\circ} \mathrm{C}, 130^{\circ} \mathrm{C}, 140{ }^{\circ} \mathrm{C}$, and $150{ }^{\circ} \mathrm{C}$ ) and then was equilibrated for $15 \mathrm{~min}$; (3) the distance between the clamps was set to $100 \mathrm{~mm}$ and the heated sample was stretched to the set stretching strain value (i.e., $5 \%, 10 \%, 15 \%$, and $20 \%$ ) at a stretching rate of $3 \mathrm{~mm} / \mathrm{min}$ by a stretching 
fixture; (4) the stretched iPP sheet with a fixed length was cooled to room temperature for testing and characterization.

\subsection{Characterization}

The X-ray diffraction (XRD) experiment was carried out on a Rigaku D/max 2550VB/PC X-ray diffractometer. The diffraction angle $2 \theta$ was measured from $3^{\circ}$ to $40^{\circ}$ The relative content of the $\beta$-modification iPP, $K_{\beta}$, was calculated by Equation (1) [16,29]:

$$
K_{\beta}=\frac{A_{\beta}(110)}{A_{\beta}(110)+A_{\alpha}(110)+A_{\alpha}(040)+A_{\alpha}(130)},
$$

where $A_{\beta}$ (110) is the area of the $\beta$-modification diffraction angle at $16.1^{\circ}$ and $A_{\alpha}(110), A_{\alpha}(040)$, and $A_{\alpha}(130)$ are the areas of the $\alpha$-modification diffraction angles at $14.1^{\circ}, 16.9^{\circ}$, and $18.5^{\circ}$, respectively.

The melting characteristics of the samples were determined by a TA-Q200 instrument. The experiment was performed in a range from 20 to $200{ }^{\circ} \mathrm{C}$. The total crystallinity, $X_{c}$, for both $\alpha$ - and $\beta$-modifications could be obtained from Equation (2):

$$
X_{C}=X_{\alpha}+X_{\beta},
$$

where $X_{\alpha}$ and $X_{\beta}$ are the crystallinity of the $\alpha$ - and $\beta$-modifications, and can be calculated by Equation (3):

$$
X_{i}=\frac{\Delta H_{i}}{\Delta H_{i}^{0}} \times 100 \%,
$$

where $\Delta H_{i}$ is the heat of fusion of the iPP sheet and $\Delta H_{i}^{0}$ is the heat of fusion of the complete crystallization of either the $\alpha$ - or the $\beta$-modification iPP (177 J/g and $168.5 \mathrm{~J} / \mathrm{g})$ [30].

A two-dimensional small-angle X-ray scattering (2D-SAXS) experiment was performed by a BL16B in the Shanghai synchrotron radiation facility (SSRF). A Pilatus detector (with $1475 \times 1679$ pixels-pixel size of $0.172 \mathrm{~mm}$ ) was equipped to collect the scattering patterns. The sample-to-detector distance was $1841 \mathrm{~mm}$. In the scattering pattern, if the pattern was isotropic or arced, the desired one-dimensional intensity distribution was obtained by multiplying $\mathrm{I}(\mathrm{q})$ by $\mathrm{q}^{2}$ for any radial scan. The one-dimensional intensity distribution $\mathrm{I}\left(\mathrm{q}_{1}\right)$ (Lorentz correction) at each $\mathrm{q}_{1}$ was calculated by using Equation (4) [31,32]:

$$
I\left(q_{1}\right)=q^{2} \times I(q)
$$

where the scattering vector $\mathrm{q}=4 \pi(\sin \theta) / \lambda, 2 \theta$ is the scattering angle, $\lambda=0.124 \mathrm{~nm}$.

The sizes of crystal could be measured from the one-dimensional correlation function $K(\mathrm{z})$, which was obtained by Equation (5) [32]:

$$
K(z)=\frac{\int_{0}^{\infty} I\left(q_{1}\right) \cos \left(q_{1} z\right) d q_{1}}{\int_{0}^{\infty} I\left(q_{1}\right) d q_{1}},
$$

where $\mathrm{z}$ denotes the stretching direction.

To observe the crystal morphology, the fracture surfaces of the samples were etched using a solution of sulfuric acid and phosphoric acid, and adding potassium permanganate for $24 \mathrm{~h}$ according to the method described by Olley [33]. The micromorphology was observed by a scanning electron microscope (S3400, Hitach, Tokyo, Japan), which had an accelerating voltage of $15 \mathrm{kV}$. All surfaces were sputtered with gold before the test.

The tensile and notched impact strength of the iPP sheet were determined by a Universal Testing Machine (RGM-2020, Shenzhen Reger Instrument, Shenzhen, China) and an Impact Testing Machine (PTM1100-B1, SUNS, Shenzhen, China), respectively. The sizes of the samples were prepared according to ASTM D638 and ASTM D256. At least five tests per data point were conducted. 


\section{Results and Discussion}

\subsection{X-ray Diffraction $(X R D)$}

The crystal structure of the iPP sheet is usually determined upon analysis of the XRD diffraction peaks. $\beta(110)$ and $\beta(111)$ are the $\beta$-modification diffraction peaks [16]. The XRD diffraction patterns of the iPP sheet at different stretching temperatures are shown in Figure 1. In Figure 1a,b, the $\beta$-modifications dominated in the crystal region of the untreated iPP sheet, and the diffraction peak intensity of the $\beta$-modifications of the stretched iPP sheet gradually decreased with an increase in the stretching strain. When the stretching temperature was below the crystallization temperature (i.e., $124^{\circ} \mathrm{C}$ ), the external force did not overcome the internal friction of the molecular chain movement of the lamellae. Deformation of the $\beta$-modification lamellae was difficult. As the stretching strain increased, part of the randomly oriented $\beta$-modification lamellae was damaged during the solid-state stretching process. Therefore, the diffraction peak intensity of $\beta(110)$ decreased.

In Figure $1 c, d$, it can be seen that the $\alpha$-modifications dominated in the crystal region when the stretching temperature exceeded the crystallization temperature of the iPP sheet. The diffraction peak intensities of the $\alpha$-modifications increased with an increase in the stretching strain, implying that transformation of the $\beta-\alpha$ modifications had occurred. It could also be found from Figure $1 c, d$ that the $\alpha$-modification diffraction peak intensities did not increase when the stretching strain exceeded $15 \%$, which indicates that the $\beta-\alpha$ phase transformation process was not dominant. In addition, the intensity of the $\beta$-modification diffraction peak was substantially unchanged, which implies that the $\beta$-modifications in the iPP sheet were not completely converted into $\alpha$-modifications. When the solid-state stretching temperature was higher (i.e., above the crystallization temperature), the molecular chain movement ability increased, which resulted in $\beta$-modification lamellae slipping and transforming into a row of $\beta$-nuclei. The molecular chains of the crystal phase grew on the surface of the thermodynamically metastable $\beta$-nuclei to form a stable $\alpha$-modification structure. When the stretching strain exceeded a critical value, the intra-lamellae molecular chains underwent stress relaxation, and the nucleus disappeared again [22]. This phenomenon was consistent with the recrystallization of iPP.

In Figure $1 \mathrm{e}$, the intensity of the dominating $\beta$-modification diffraction peak, $\beta(110)$, significantly decreased with the increase in the stretching strain, while the intensity of the $\alpha$-modification diffraction peaks increased relative to the unstretched $\beta$-modification iPP sheet. The $\beta$-modifications were more likely to melt to recrystallize under external force when the stretching temperature was $150{ }^{\circ} \mathrm{C}$ (i.e., near the melting point of the $\beta$-modifications). Furthermore, oriented $\alpha$-nucleation occurred, which increased the content of $\alpha$-modifications in the iPP sheet.

In summary, the $\beta-\alpha$ phase transformation process occurred in the $\beta$-modification iPP sheet after solid-state stretching below the melting point. When the stretching temperature was too low, the movement ability of the molecular chains was poor, and the phase transformation process did not occur. When the stretching temperature was too high, $\beta$-modification lamellae underwent thermodynamic relaxation and were converted into $\alpha$-modification lamellae. Once the stretching strain exceeded a critical strain value of $15 \%, \beta-\alpha$ phase transformation did not continue to increase. This may be explained by the fact that at higher temperatures, the relaxation effect of the molecular chains was stronger than the orientation effect at a higher stretching strain, and the entanglements of the iPP molecular chains prevented the phase transformation process. 

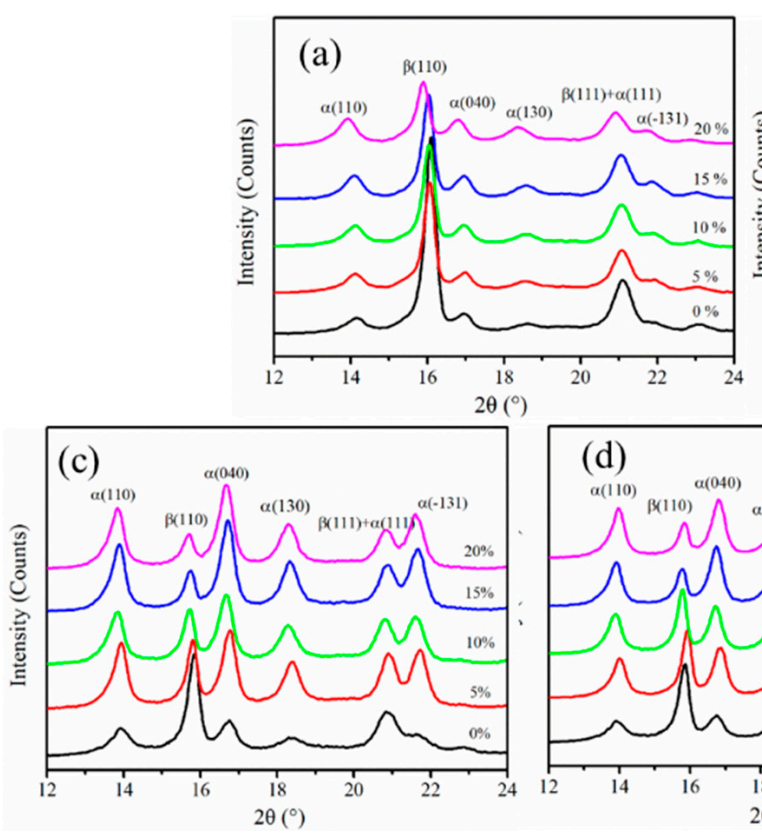

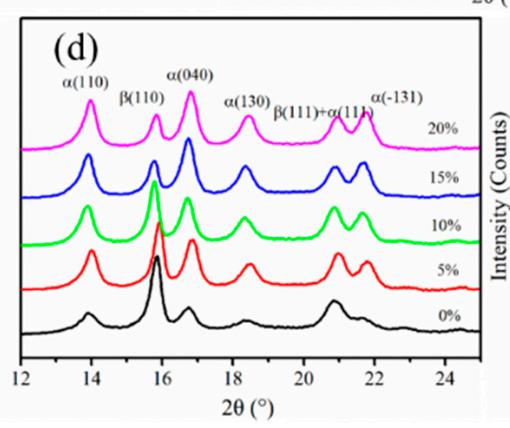

Figure 1. X-ray diffraction (XRD) curves of the isotactic polypropylene (iPP) sheet after stretching at different temperatures: (a) $110^{\circ} \mathrm{C}$, (b) $120^{\circ} \mathrm{C}$, (c) $130{ }^{\circ} \mathrm{C}$, (d) $140{ }^{\circ} \mathrm{C}$, and (e) $150{ }^{\circ} \mathrm{C}$.

The relative fraction of $\beta$-modifications $\left(\mathrm{K}_{\beta}\right.$, obtained from Equation (1)) of the iPP sheet are shown in Figure 2. It was known that $\mathrm{K}_{\beta}$ decreased with an increase in the stretching temperature. When the stretching temperature was lower, $K_{\beta}$ decreased slowly because fewer $\beta$-modification lamellae were damaged by stretching. When the stretching temperature was above the crystallization temperature (i.e., $124^{\circ} \mathrm{C}$ ), $\mathrm{K}_{\beta}$ also showed a downward trend. Therefore, the phase transformation process occurred, owing to the slippage and rearrangement of the molecular chains of the lamellae. The change in $\mathrm{K}_{\beta}$ was small when the stretching strain was between $15 \%$ and $20 \%$, which can be explained by the stress relaxation accelerating the slippage of the newly formed $\alpha$-modifications. However, $\mathrm{K}_{\beta}$ rapidly decreased to near zero once the stretching temperature increased to $150{ }^{\circ} \mathrm{C}$, during which time, a large number of $\alpha$-nuclei were generated. Subsequently, the molecular chains were folded on its surface to produce $\alpha$-modifications.

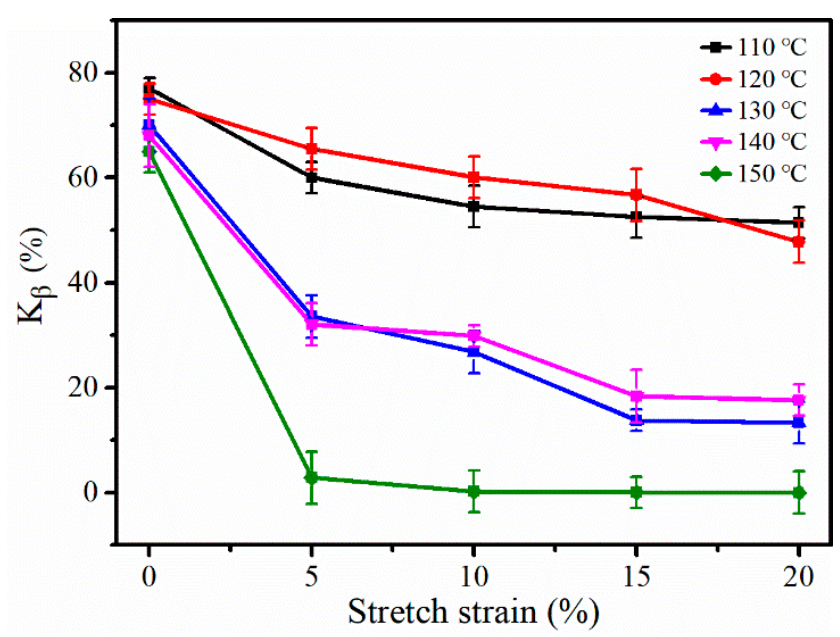

Figure 2. The $\mathrm{K}_{\beta}$ of the iPP sheet after stretching at different temperatures. 


\subsection{Differential Scanning Calorimetry (DSC)}

The melting characteristics of the iPP sheet at different stretching temperatures are shown in Figure 3. The endothermic peak located at $150{ }^{\circ} \mathrm{C}$ was the melting point of the $\beta$-modifications $\left(T_{m} \beta\right)$, while that located at $165^{\circ} \mathrm{C}$ was the melting point of the $\alpha$-modifications $\left(T_{m \alpha}\right)$ [28]. In Figure 3a,b, the melting enthalpy of the $\alpha$ - and $\beta$-modifications did not change much after solid-state stretching. This can be explained by the fact that the solid-state stretching effect was not large enough to induce the phase transformation process at lower stretching temperatures. However, in Figure $3 c, d$, the crystal structure of the iPP sheet was mainly that of the $\alpha$-modifications when the stretching temperature exceeded the recrystallization temperature. Furthermore, the melting peak of the $\beta$-modifications decreased until it eventually disappeared. The $\beta$-modification lamellae were stretched and slipped, owing to the thermodynamic metastability; thus, $\beta-\alpha$ phase transformation was accelerated. Figure $3 c, d$ also shows that the melting points of the $\alpha$ - and $\beta$-modifications moved in the high-temperature direction after solid-state stretching, implying that the amorphous molecular chains were stretched.

The melting curve of the iPP sheet at a stretching temperature of $150^{\circ} \mathrm{C}$ is shown in Figure 3e. It was difficult to observe the melting peak of the $\beta$-modifications, indicating that almost all the $\beta$-modifications were transformed into thermodynamically stable $\alpha$-modifications. The higher stretching temperature accelerated the movement of intra-lamellae molecular chains, which was favorable for the conformation of the $\alpha$-modifications.
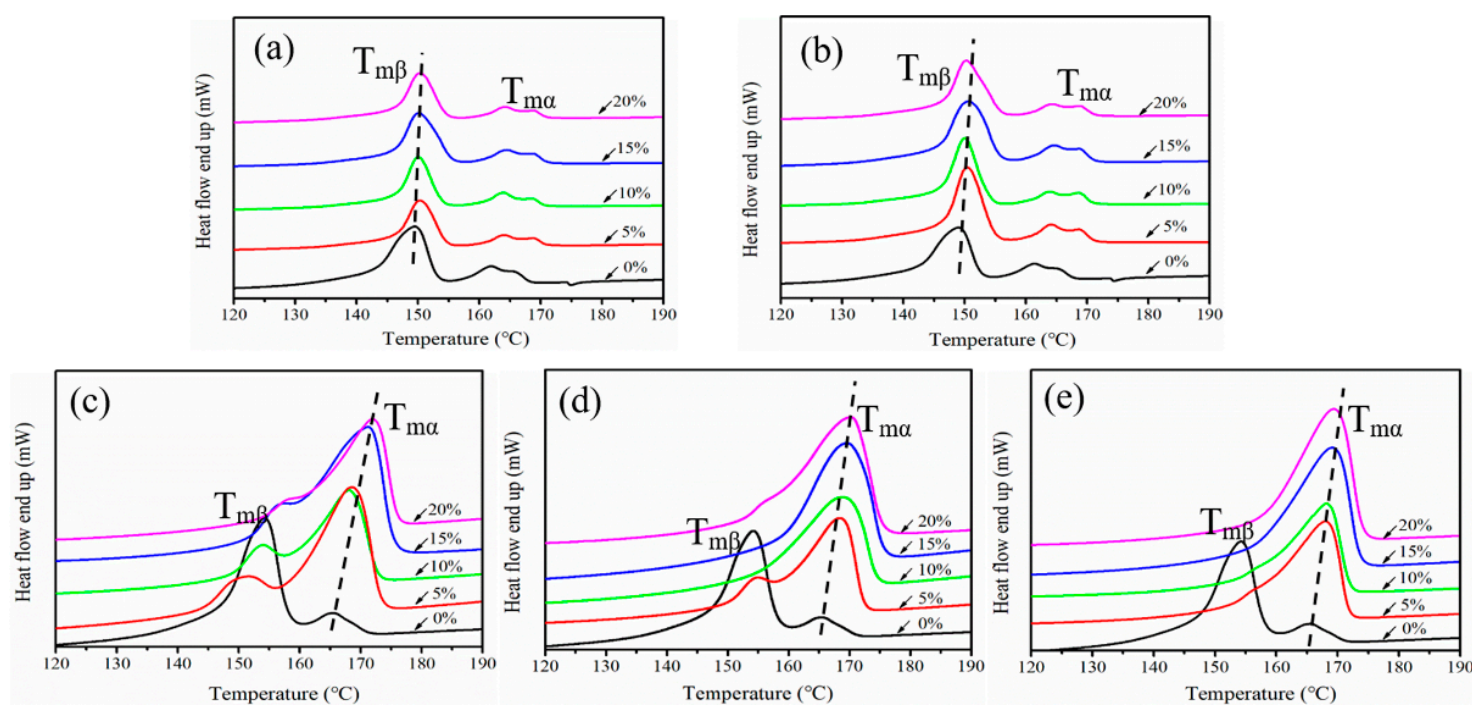

Figure 3. The melting curves of the iPP sheet after stretching at different temperatures: (a) $110{ }^{\circ} \mathrm{C}$, (b) $120^{\circ} \mathrm{C}$, (c) $130{ }^{\circ} \mathrm{C}$, (d) $140{ }^{\circ} \mathrm{C}$, and (e) $150{ }^{\circ} \mathrm{C}$.

For semi-crystalline polymers, crystallinity is an important factor for the properties of the material [34]. The total crystallinity ( $X_{c}$, obtained from Equations (2) and (3)) of the iPP sheet at different stretching temperatures is shown in Figure 4. The $X_{c}$ increased with an increase in the stretching temperature because of the oriented molecular chains. While the stretching temperature was below the crystallization temperature, the phase transformation process did not occur due to the large internal friction of the movement of the lamellae. Therefore, $X_{c}$ did not change greatly with an increase in the stretching strain. When the stretching temperature was $130 \sim 140{ }^{\circ} \mathrm{C}$, according to the previous results, the $\beta$-modifications gradually transformed into $\alpha$-modifications. As the stretching strain was increased from $5 \%$ to $15 \%, X_{c}$ increased slowly, implying that the external force work mainly promoted the crystal phase transformation and had little effect on the crystallinity. When the stretching strain was $20 \%$, the degree of the molecular chain orientation of the iPP sheet increased, which promoted the process of crystallization. When the stretching temperature was $150{ }^{\circ} \mathrm{C}$, the transformation from $\beta$-modifications to $\alpha$-modifications resulted in an increase in the crystallinity. 


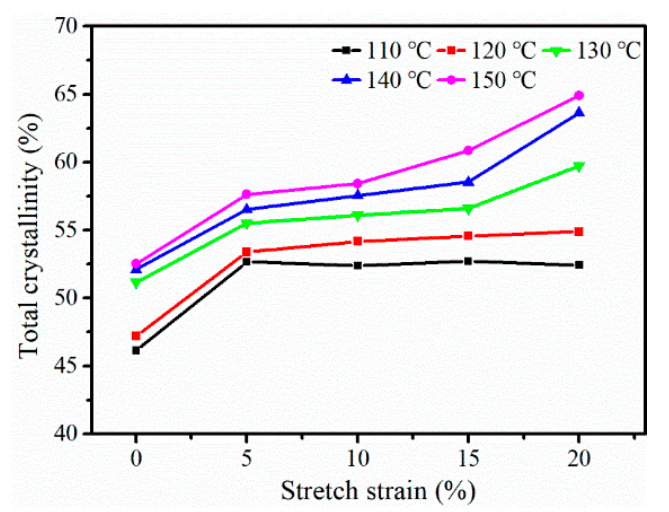

Figure 4. Total crystallinity of the iPP sheet after stretching at different temperatures.

\section{3. $2 D$ Small-Angle X-ray Scattering (2D-SAXS)}

According to the results of XRD and DSC, solid-state stretching is able to induce the phase transformation process of an iPP sheet, but is unable to explain the orientation change of the crystal lamellae. The 2D-SAXS patterns during uniaxial stretching of the iPP sheet are shown in Figure 5. When the stretching temperature was below the crystallization temperature, the scattering patterns had no orientation under $10 \%$ stretching strain, implying that isotropic $\beta$-modifications dominated in the matrix. As the stretching strain increased, the difference in the electron densities along the stretch direction increased, which indicates that the intra-lamellae molecular chains were stretched. As a result, oriented $\beta$-modifications were generated. In addition, a scattering peak perpendicular to the stretching direction was not found, indicating that the phase transformation process did not occur. This result can be explained by the fact that the extended inter-lamellae molecular chains relaxed rapidly due to the short time of the external force action. At that moment, the external force was insufficient to change the crystal lamellae structure of the iPP sheet.

When the stretching temperature was $130 \sim 140^{\circ} \mathrm{C}$, an "inverted triangle" peak (marked by red arrows) was also observed, which suggests that a cylindrite structure of stable orientation existed in the iPP sheet. Because the orientation of the amorphous molecular chains had restricted movement and formed a "kebab" structure, the $\beta$-modification lamellae were broken and formed a "shish" structure along the stretching direction [35]. However, when the stretching temperature was $150{ }^{\circ} \mathrm{C}$, the amorphous molecular chain had a large space for movement due to the destruction of a large number of lamellae, and the number of nucleation sites increased. As a result, shish-kebab cylindrite structures were no longer observed due to large amount of recrystallization at the elevated temperature. Hobeika et al. [36] studied the change of the lamellae structure of HDPE (High Density Polyethylene) during the temperature-deformation process. The critical strain point of the lamellae slippage was obtained by using the true stress-strain curve. The results showed that the yield strain was always around 0.12 at different temperatures or strain rates. The premise of the lamellae phase transformation process was that the lamellar could be stretched and slipped. In Figure 5, an orientation diffraction peak perpendicular to the stretching direction appeared after solid-state stretching of $10 \%$ strain at $130^{\circ} \mathrm{C}$ and $140^{\circ} \mathrm{C}$. There were two reasons for this: on the one hand, the stretching temperature was higher than the iPP crystallization temperature (i.e., $124^{\circ} \mathrm{C}$ ), and the stability of the molecular chains of the lamellae was poor; on the other hand, the stretching strain was defined based on the displacement of the fixture movement. If it was converted into true stress-strain, the strain would exceed $10 \%$.

The evolution of the microstructure of the $\beta$-modifications mainly depended on the stretching temperature. When the temperature was lower, the molecular chains were poorly oriented. When the temperature exceeded the crystallization temperature, the phase transformation process occurred, owing to the restricted movement of the molecular chains of the lamellae. A small amount of shish-kebab cylindrite structure was formed. When the stretching temperature was near the $\beta$-modification melting point, a large number of lamellae were destroyed and recrystallized. Almost all $\alpha$-modifications were crystallized in the system. The shish-kebab structure collapsed due to stress relaxation to the 
$\alpha$-modifications. Therefore, solid-state stretching did not continuously enhance the ability of the transformation of $\beta$-modifications, and the shish-kebab cylindrite structure was produced only at $130 \sim 140{ }^{\circ} \mathrm{C}$.

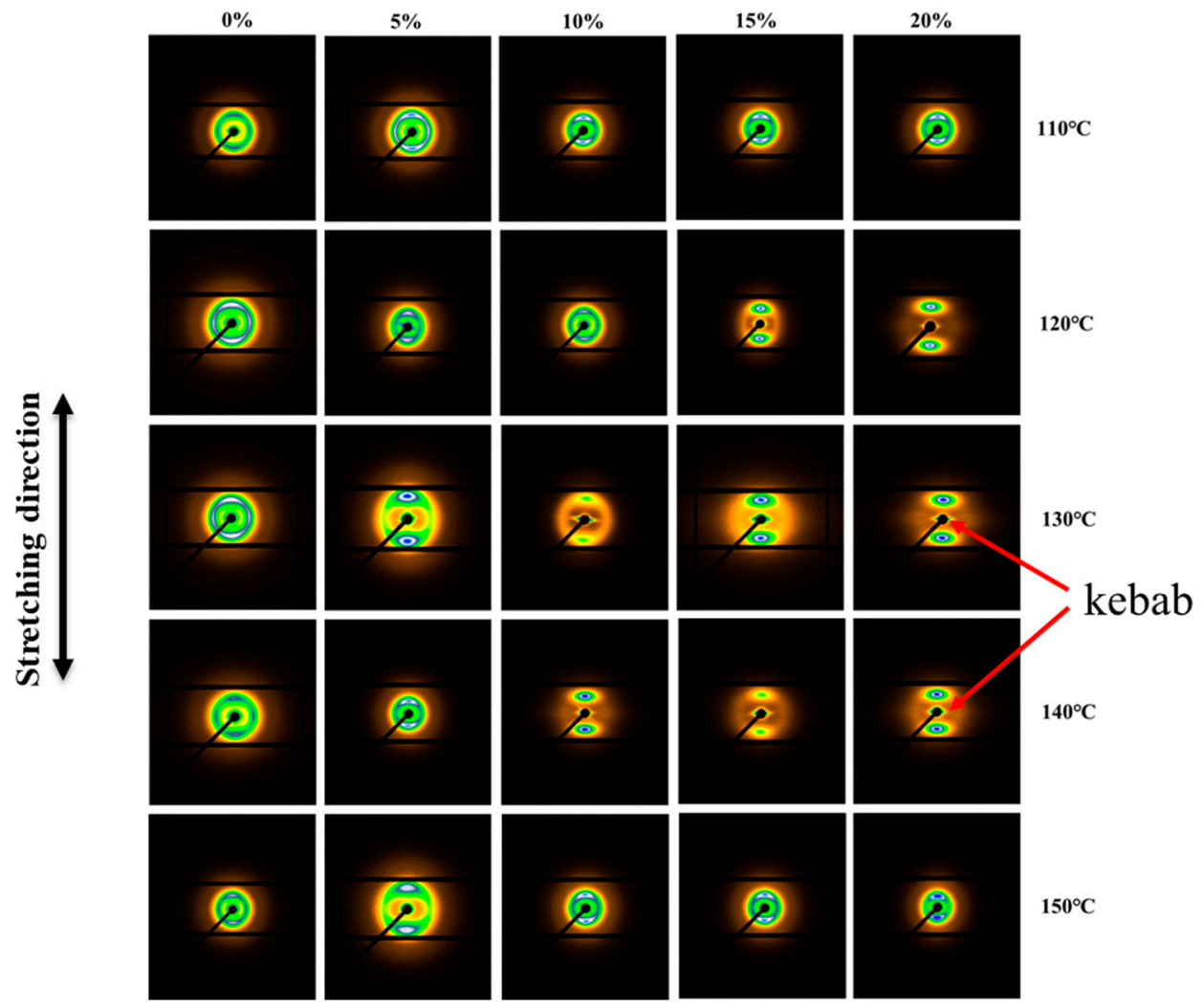

Figure 5. Two-dimensional small-angle X-ray scattering (2D-SAXS) patterns of the iPP sheet after stretching at different temperatures.

The above research results show that solid-state stretching can induce changes to the microstructure of the iPP sheet. To investigate the effect of solid-state stretching deformation on the sizes of the crystals, K(z) (obtained from Equations (4) and (5)) curves of the iPP sheet are shown in Figure 6. The parameters were derived from the $K(z)$ curve (Figure $6 a)$. The long period $d_{a c}$ is the average spacing between lamellae, and the lamellar thickness $d_{c}$ was obtained by subtracting the inter-lamellae coil molecular chain layer thickness from the long period. However, the crystallinity of the sample used in the present study was higher than 0.5. Thus, the smaller value $d_{a}$ was defined as the average thickness of the inter-lamellae coil molecular chain layer [32,37].

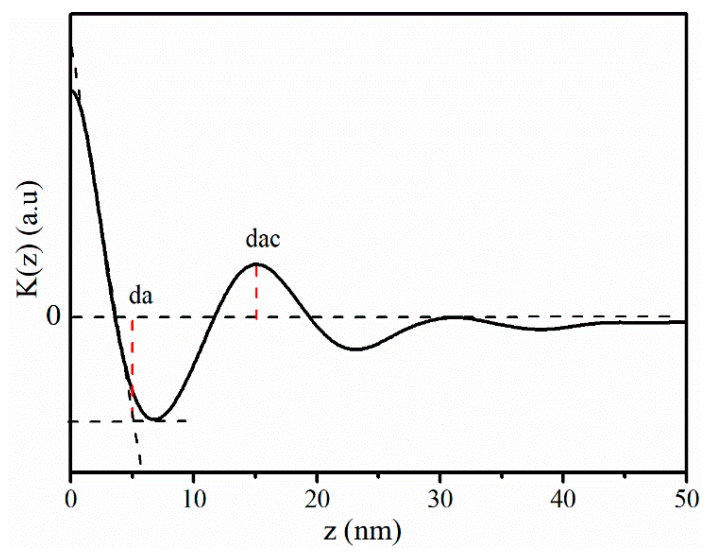

Figure 6. $\mathrm{K}(\mathrm{z})$ of the iPP sheet after solid-state stretching. 
The $d_{a c}$ and $d_{c}$ derived from Figure 6 are shown in Figure 7. In Figure 7a, when the stretching temperature was $110 \sim 120{ }^{\circ} \mathrm{C}, \mathrm{d}_{\mathrm{ac}}$ increased with increasing stretch strain. This was because the molecular chains between the adjacent lamellae were stretched. When the stretching temperature gradually increased to $130 \sim 140{ }^{\circ} \mathrm{C}$, it was observed that the $\mathrm{d}_{\mathrm{ac}}$ decreased slightly. It was clear, based on the research results in Figure 5, that a stable shish-kebab structure had been formed. Simultaneously, when the stretching strain continued to increase, the embedding of the inter-lamellae molecular chains counteracted the increased distance between adjacent lamellae, which could also explain the reduction in $d_{a c}$. Mao et al. [38] studied the influence of the deformation induced on the $d_{a c}$ of iPP. They exposed that the $\mathrm{d}_{\mathrm{ac}}$ decreased due to densely packed lamellae, and then increased owing to the separation of lamellae. When the stretching temperature was $150{ }^{\circ} \mathrm{C}, \mathrm{d}_{\mathrm{ac}}$ decreased with the increasing stretch strain. This can be explained by the fact that the crystal lamellae of the iPP sheet melted and formed $\alpha$-modification nucleation sites at a higher temperature, which induced the transformation of $\beta-\alpha$ modifications; $\alpha$-modifications were densely packed, and the long period decreased.

The $d_{c}$ values of the stretched iPP sheet are shown in Figure $7 b$. It can be found that $d_{c}$ remained substantially unchanged when the stretching temperature was low. There was no phase transformation process because the iPP crystal lamellae were not stretched. When the stretching temperature was $130 \sim 140{ }^{\circ} \mathrm{C}, \mathrm{d}_{\mathrm{c}}$ decreased as the stretching strain increased from $10 \%$ to $15 \%$. On the one hand, a shish-kebab structure was produced, which resulted in a reduction in $d_{c}$. On the other hand, some $\alpha$-modification nuclei were generated when the lamellae were broken, and the crystal nuclei crystallized into $\alpha$-modifications. Therefore, it can be concluded that the application of an external force contributed substantially to the phase transformation process, rather than the simple molecular chain orientation. When the stretching temperature was $150^{\circ} \mathrm{C}$, the molecular chain was more easily stretched and oriented, which resulted in an increase in $d_{c}$. The melting and recrystallization of the $\beta$-modifications transformed into stable $\alpha$-modifications, so that the shish-kebab-like structure was absent. With an increase of the stretching strain, the external force mainly resulted in the destruction of the lamellae and produced $\alpha$-nuclei. Therefore, the $d_{c}$ increased.
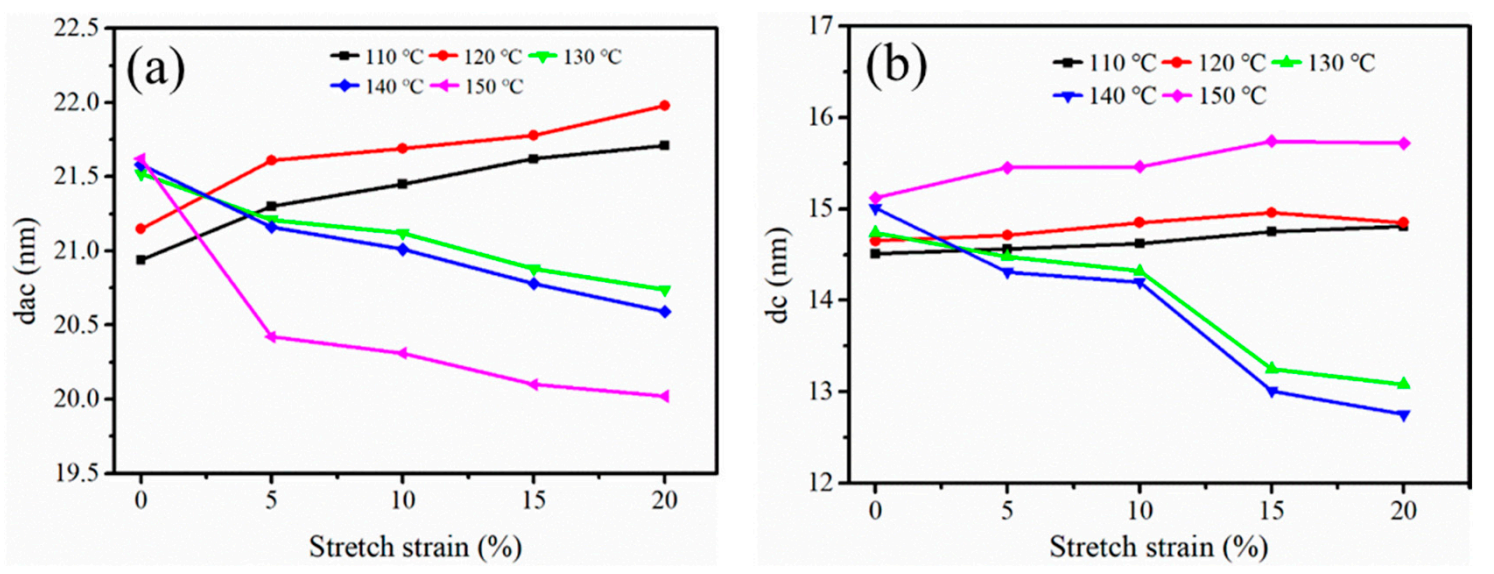

Figure 7. The $d_{a c}$ and $d_{c}$ of the iPP sheet after stretching at different temperatures.

\subsection{Scanning Electron Microscopy (SEM)}

Scanning electron microscopy (SEM) micrographs illustrate a crystalline morphology is present during the solid-state stretching process. The micrographs of the iPP sheet are shown in Figure 8. When the initial iPP sheets were annealed at different temperatures, densely and randomly oriented $\beta$-modifications were observed. This shows that annealing could not promote the structural rearrangement of the molecular chains of the $\beta$-modification lamellae, and the crystal phase transformation process did not occur. When the stretching temperature was below the crystallization temperature (Figure 8a,b), a $\beta$-bundle crystal structure was observed [39-41], indicating that $\beta$-modifications dominated in the system. Oriented lamellae were not observed along the stretching 
direction, implying that the amorphous molecular chains were oriented, but that the lamellae were not stretched. This was because the external force was not sufficient to provide the energy to promote molecular chain movement. When the stretching temperature was $130^{\circ} \mathrm{C}$ (Figure 8c), a cylindrite morphology could be observed when the stretching strain was between $10 \%$ and $20 \%$. This can be explained by the fact that the molecular chains between the orientated lamellae and the partial $\beta$-modifications transformed into oriented cylindrites. Typically, a shish-kebab-like structure was produced due to slippage of lamellae in thermodynamic metastable $\beta$-modifications. Similar tendencies were observed in Figure 8d. Furthermore, it was found that the cylindrite structure at $130{ }^{\circ} \mathrm{C}$ was more stable, revealing that the regulation of macromechanical properties was greater.

The micrographs of the iPP sheet after solid-state stretching at $150{ }^{\circ} \mathrm{C}$ are shown in Figure $8 \mathrm{e}$. The $\beta$-modifications almost completely disappeared, and the $\alpha$-modifications dominated in the crystal region. This can be explained by the fact that most of the $\beta$-modifications melted, and the disordered molecular chains crystallized in the $\alpha$-spherulite structure. This result corresponds to the XRD analysis results.

(a)
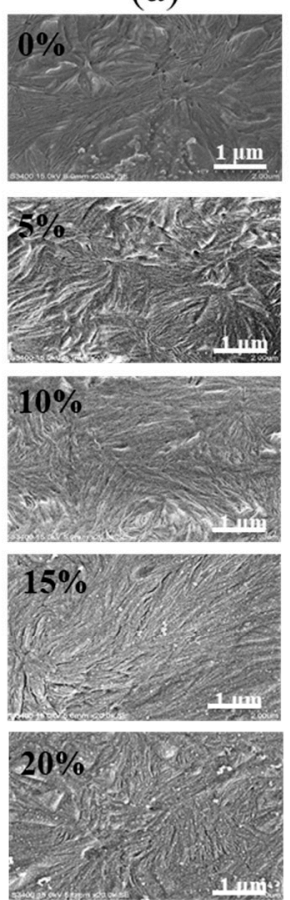

(b)
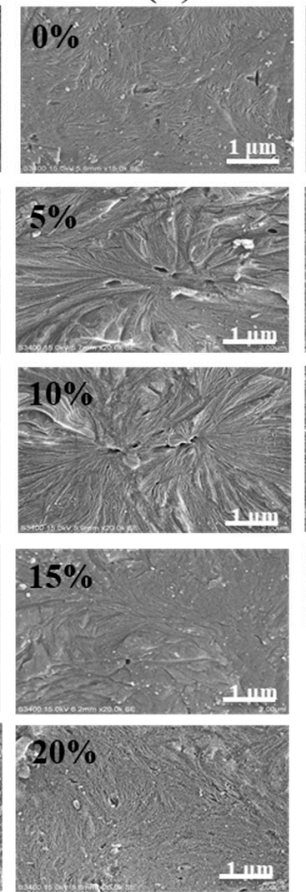

(c)
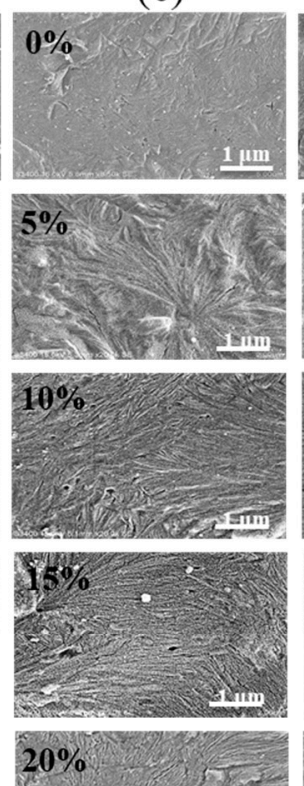

(d)
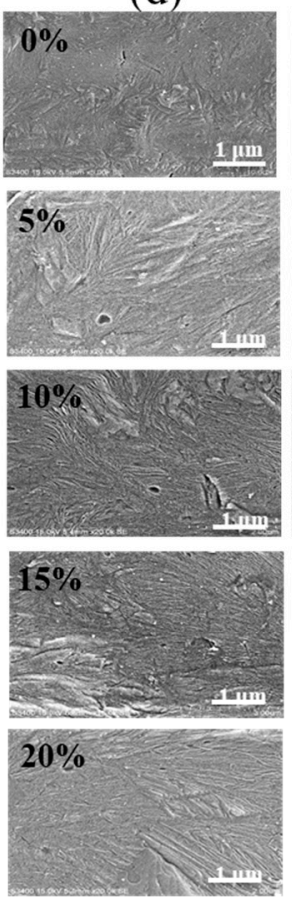

(e)
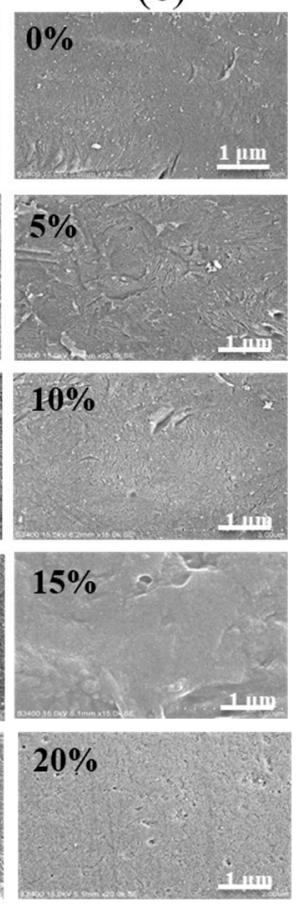

Figure 8. Scanning electron microscopy micrographs of the iPP sheet after stretching at different temperatures: (a) $110{ }^{\circ} \mathrm{C}$, (b) $120^{\circ} \mathrm{C}$, (c) $130{ }^{\circ} \mathrm{C}$, (d) $140{ }^{\circ} \mathrm{C}$, and (e) $150{ }^{\circ} \mathrm{C}$. The arrow indicates the stretching direction.

\subsection{Mechanical Properties}

It is well known that the mechanical properties of iPP sheets are related not only to crystallinity, but also to the micromorphology of the crystal structure. The mechanical properties of the iPP sheet in this study at different stretching temperatures are shown in Figure 9. In Figure 9a, the tensile strength increased under increased stretching. When the stretching temperature was $150^{\circ} \mathrm{C}$, the tensile strength increased by $34 \%$ as the stretching strain increased to $20 \%$. The molecular chain orientation promoted an increase in the total crystallinity, which resulted in an increase in tensile strength [42]. In addition, the $\beta$-modifications in the iPP sheet system were almost completely melted and recrystallized to $\alpha$-modifications, which improved the tensile strength. Figure $9 \mathrm{~b}$ shows the notched impact strength of the iPP sheet. It was found that the notched impact toughness increased with the increasing of 
the stretching strain when the stretching temperature was $110 \sim 120^{\circ} \mathrm{C}$. Thus, it was concluded that the molecular chains were oriented. When the stretching temperature exceeded the crystallization temperature, the notched impact strength of the iPP sheet after $15 \%$ stretching strain at $130^{\circ} \mathrm{C}$ increased by $126 \%$ compared to the initial iPP sheet. According to the analysis results in Figure 5, there was a crystal phase transfer process in the system at this time, and a shish-kebab cylindrite structure existed. The metastable shish-kebab cylindrite structure could absorb more energy to transform into a stable crystal structure. Thus, the impact toughness was significantly improved [43]. When the stretching strain was $20 \%$, the shish-kebab-like crystal phase transfer process did not dominate. As a result, the impact toughness was reduced.
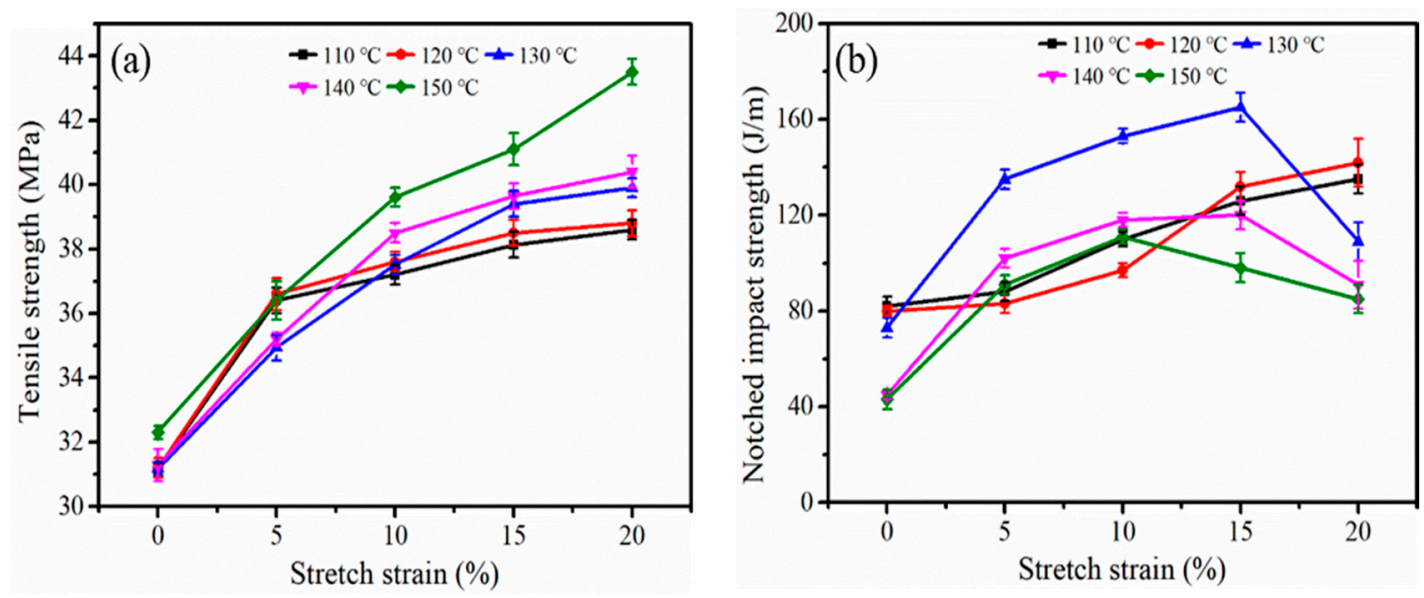

Figure 9. The tensile strength (a) and the notched impact strength (b) of the iPP sheet after stretching at different temperatures.

\subsection{Cylindrite Structure Transformation Mechanism}

Upon deformation, the isotropic structure of polymer can be transformed into an anisotropic structure [28]. Hence, the transition mechanism and the relationship to the morphology and structure are important for polymer science. When the solid-state stretching temperature was higher than the crystallization temperature, the free energy of the crystallization of the molecular chain of the lamellar was low, and the folded lamellae were stretched and oriented. A schematic diagram reflecting the transformation of $\beta$-modification is shown in Figure 10. As the stretching strain was smaller, the application of an external force mainly promoted the disentanglement and extension of the amorphous-phase molecular chains, and the $\beta$-phase remained an isotropic spherulite structure. The inter-lamellar molecular chain underwent reversible elastic deformation, and no phase transformation occurred in this process. As the stretching strain increased, the $\beta$-phase lamellae was deflected and formed an oriented $\beta$-phase structure. As the stretching strain continued to increase, the $\beta$-phase lamellae was subjected to the persistent loading, extensive lamellae slippage inevitably caused the fragmentation of lamellae. In addition, part of the lamellae chains were pulled out. Subsequently, the lamellae chains were stretched and extended to form a shish-like structure [44,45]. RJ Young [46] suggested that when the spherulites were deforming homogeneously, the crystalline regions deformed by a combination of slipping, twinning, and martensitic transformation during the stage of deformation. As the stretching strain was higher, the fragmentation of lamellae started to rotate and surround the surface of the shish structure perpendicular to the stretching direction and formed a kebab structure, eventually forming a stable shish-kebab structure. Besides, random molecular chains were folded and grew epitaxially on the surface of the shish structure to form a shish-kebab structure. 


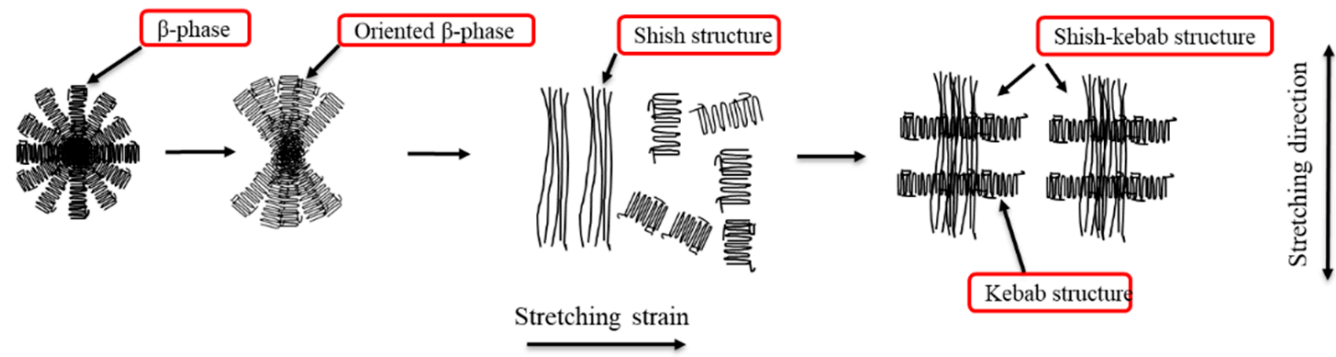

Figure 10. A schematic diagram reflecting the transformation of $\beta$-modifications for the stretched iPP sheet.

\section{Conclusions}

This study investigated the deformation-induced crystal process of an iPP sheet containing the TMB-5 nucleating agent. The crystal orientation and the transformation of the iPP sheet were evaluated during a solid-state stretching process. $\beta$-modification lamellae were broken and a shish-kebab cylindrite structure was crystallized when the stretching temperature was above the crystallization temperature. Subsequently, the $\beta-\alpha$ transformation process occurred based on the existence of stress relaxation as the stretching temperature increased. The long period and the thickness of the crystal layer of the stretched iPP sheet were decreased during $\beta$-phase transformation into cylindrite. The crystal phase transformation process was conducive to improving the mechanical properties of the material. After $15 \%$ solid-state stretching at $130{ }^{\circ} \mathrm{C}$, the notched impact strength of the stretched iPP sheet increased by $126 \%$. Thus, we have significantly demonstrated that solid-state stretching of iPP sheets plays an important role, influences the morphology, and, as a result, can improve both the stiffness and the toughness of iPP.

Author Contributions: Conceptualization, L.X.; methodology, H.J. and L.X.; software, X.C.; validation, H.Z. and Y.W.; formal analysis, H.J. and H.Z.; investigation, H.J.; resources, L.X.; data curation, X.Z.; writing-original draft preparation, H.J.; writing-review and editing, L.X. and H.J.; visualization, X.Z.; supervision, Y.M.; project administration, L.X.; funding acquisition, L.X. All authors have read and agreed to the published version of the manuscript.

Funding: This research was funded by the National Natural Science Foundation of China, grant number 51273065.

Conflicts of Interest: There are no conflicts of interest for any authors.

\section{References}

1. Krache, R.; Benavente, R.; López-Majad, J.M.; Pérez, E. Competition between $\alpha$, $\beta$, and $\gamma$ Polymorphs in a $\beta$-Nucleated Metallocenic Isotactic Polypropylene. Macromolecules 2007, 40, 6871-6878. [CrossRef]

2. Mao, Y.; Burger, C.; Li, X.; Hsiao, B.S.; Mehta, A.K.; Tsou, A.H. Time-Resolved Synchrotron X-ray Scattering Study on Propylene-1-Butylene Random Copolymer Subjected to Uniaxial Stretching at High Temperatures. Macromolecules 2012, 45, 951-961. [CrossRef]

3. Sheng, Q.; Zhang, Y.; Xia, C.; Mi, D.; Xu, X.; Wang, T.; Zhang, J. A new insight into the effect of $\beta$ modification on the mechanical properties of iPP: The role of crystalline morphology. Mater. Des. 2016, 95, 247-255. [CrossRef]

4. Han, L.; Li, X.; Li, Y.; Huang, T.; Wang, Y.; Wu, J.; Xiang, F. Influence of annealing on microstructure and physical properties of isotactic polypropylene/calcium carbonate composites with $\beta$-phase nucleating agent. Mater. Sci. Eng. A 2010, 527, 3176-3185. [CrossRef]

5. Zhao, S.; Liu, K.; Zhou, S.; Shi, Y.; Xin, Z. A novel self-dispersed $\beta$ nucleating agent for isotactic polypropylene and its unique nucleation behavior and mechanism. Polymer 2017, 132, 69-78. [CrossRef]

6. Chen, H.B.; Karger-Kocsis, J.; Wu, J.S.; Varga, J. Fracture toughness of $\alpha$ - and $\beta$-phase polypropylene homopolymers and random- and block-copolymers. Polymer 2002, 43, 6505-6514. [CrossRef]

7. Zhang, B.; Chen, J.; Ji, F.; Zhang, X.; Zheng, G.; Shen, C. Effects of melt structure on shear-induced $\beta$-cylindrites of isotactic polypropylene. Polymer 2012, 53, 1791-1800. [CrossRef] 
8. Tordjeman, P.; Robert, C.; Marin, G.; Gerard, P. The effect of $\alpha, \beta$ crystalline structure on the mechanical properties of polypropylene. Eur. Phys. J. E 2001, 4, 459-465. [CrossRef]

9. Byelov, D.; Panine, P.; Remerie, K.; Biemond, E.; Alfonso, G.C.; de Jeu, W.H. Crystallization under shear in isotactic polypropylene containing nucleators. Polymer 2008, 49, 3076-3083. [CrossRef]

10. Zuo, F.; Keum, J.K.; Chen, X.; Hsiao, B.S.; Chen, H.; Lai, S.-Y.; Wevers, R.; Li, J. The role of interlamellar chain entanglement in deformation-induced structure changes during uniaxial stretching of isotactic polypropylene. Polymer 2007, 48, 6867-6880. [CrossRef]

11. Huo, H.; Jiang, S.; An, L. Influence of Shear on Crystallization Behavior of the $\beta$ Phase in Isotactic Polypropylene with $\beta$-Nucleating Agent. Macromolecules 2004, 37, 2478-2483. [CrossRef]

12. Xiao, W.; Wu, P.; Feng, J.; Yao, R. Influence of a novel $\beta$-nucleating agent on the structure, morphology, and nonisothermal crystallization behavior of isotactic polypropylene. J. Appl. Polym. Sci. 2009, 111, 1076-1085. [CrossRef]

13. Wang, S.-W.; Yang, W.; Xu, Y.-J.; Xie, B.-H.; Yang, M.-B.; Peng, X.-F. Crystalline morphology of $\beta$-nucleated controlled-rheology polypropylene. Polym. Test. 2008, 27, 638-644. [CrossRef]

14. Juhász, P.; Varga, J.; Belina, K.; Marand, H. Determination of the equilibrium melting point of the $\beta$-form of polypropylene. J. Therm. Anal. Calorim. 2002, 69, 561-574. [CrossRef]

15. Varga, J.; Menyhard, A. Effect of Solubility and Nucleating Duality of N,N'-Dicyclohexyl-2,6naphthalenedicarboxamide on the Supermolecular Structure of Isotactic Polypropylene. Macromolecules 2007, 40, 2422-2431. [CrossRef]

16. Slouf, M.; Pavlova, E.; Krejcikova, S.; Ostafinska, A.; Zhigunov, A.; Krzyzanek, V.; Sowinski, P.; Piorkowska, E. Relations between morphology and micromechanical properties of alpha, beta and gamma phases of iPP. Polym. Test. 2018, 67, 522-532. [CrossRef]

17. Lezak, E.; Bartczak, Z.; Galeski, A. Plastic Deformation of the $\gamma$ Phase in Isotactic Polypropylene in Plane-Strain Compression. Macromolecules 2006, 39, 4811-4819. [CrossRef]

18. Van Erp, T.B.; Balzano, L.; Spoelstra, A.B.; Govaert, L.E.; Peters, G.W.M. Quantification of non-isothermal, multi-phase crystallization of isotactic polypropylene: The influence of shear and pressure. Polymer 2012, 53, 5896-5908. [CrossRef]

19. Shi, G.-Y.; Chu, F.; Zhou, G.-E.; Han, Z.-W. Plastic deformation and solid-phase transformation in $\beta$-phase polypropylene. Die Makromol. Chem. 1989, 190, 907-913. [CrossRef]

20. Wu, G.-G.; Chen, W.-B.; Ding, C.; Xu, L.-Y.; Liu, Z.-Y.; Yang, W.; Yang, M.-B. Pore formation mechanism of oriented $\beta$ polypropylene cast films during stretching and optimization of stretching methods: In-situ SAXS and WAXD studies. Polymer 2019, 163, 86-95. [CrossRef]

21. Li, J.X.; Cheung, W.L. On the deformation mechanisms of $\beta$-polypropylene: 1 . Effect of necking on $\beta$-phase PP crystals. Polymer 1998, 39, 6935-6940. [CrossRef]

22. Bao, R.-Y.; Ding, Z.-T.; Liu, Z.-Y.; Yang, W.; Xie, B.-H.; Yang, M.-B. Deformation-induced structure evolution of oriented $\beta$-polypropylene during uniaxial stretching. Polymer 2013, 54, 1259-1268. [CrossRef]

23. Riekel, C.; Karger-Kocsis, J. Structural investigation of the phase transformation in the plastic zone of a $\beta$-phase isotactic polypropylene by synchrotron. Polymer 1999, 40, 541-545. [CrossRef]

24. Lezak, E.; Bartczak, Z.; Galeski, A. Plastic deformation behavior of $\beta$-phase isotactic polypropylene in plane-strain compression at room temperature. Polymer 2006, 47, 8562-8574. [CrossRef]

25. Boyanova, M.; Calleja, F.J.B.; Fakirov, S. New aspects of the $\beta-\alpha$ polymorphic transition in plastically deformed isotactic polypropylene studied by microindentation hardness. J. Mater. Sci. 2006, 41, 5504-5509. [CrossRef]

26. Zuo, F.; Mao, Y.; Li, X.; Burger, C.; Hsiao, B.S.; Chen, H.; Marchand, G.R. Effects of Block Architecture on Structure and Mechanical Properties of Olefin Block Copolymers under Uniaxial Deformation. Macromolecules 2011, 44, 3670-3673. [CrossRef]

27. Rozanski, A.; Galeski, A.; Debowska, M. Initiation of Cavitation of Polypropylene during Tensile Drawing. Macromolecules 2011, 44, 20-28. [CrossRef]

28. Ji, H.; Zhou, X.; Chen, X.; Zhao, H.; Wang, Y.; Zhu, H.; Shan, X.; Sha, J.; Ma, Y.; Xie, L. Effects of Solid-State Stretching on Microstructure Evolution and Physical Properties of Isotactic Polypropylene Sheets. Polymers 2019, 11, 618. [CrossRef] 
29. Chen, Y.-H.; Fang, D.-F.; Lei, J.; Li, L.-B.; Hsiao, B.S.; Li, Z.-M. Shear-Induced Precursor Relaxation-Dependent Growth Dynamics and Lamellar Orientation of $\beta$-Crystals in $\beta$-Nucleated Isotactic Polypropylene. J. Phys. Chem. B 2015, 119, 5716-5727. [CrossRef]

30. Varga, J. ß-modification of isotactic polypropylene: Preparation, structure, processing, properties, and application. J. Macromol. Sci. Phys. 2002, 41, 1121-1171. [CrossRef]

31. Matyi, R.J.; Crist, B., Jr. Small-angle x-ray scattering by nylon 6. J. Polym. Sci. Polym. Phys. Ed. 1978, 16, 1329-1354. [CrossRef]

32. Jiang, Z.; Tang, Y.; Rieger, J.; Enderle, H.-F.; Lilge, D.; Roth, S.V.; Gehrke, R.; Heckmann, W.; Men, Y. Two Lamellar to Fibrillar Transitions in the Tensile Deformation of High-Density Polyethylene. Macromolecules 2010, 43, 4727-4732. [CrossRef]

33. Olley, R.H.; Bassett, D.C. An improved permanganic etchant for polyolefines. Polymer 1982, 23, $1707-1710$. [CrossRef]

34. Niu, H.; Wang, N.; Li, Y. Influence of $\beta$-nucleating agent dispersion on the crystallization behavior of isotactic polypropylene. Polymer 2018, 150, 371-379. [CrossRef]

35. Han, R.; Nie, M.; Wang, Q.; Yan, S. Self-Assembly $\beta$ Nucleating Agent Induced Polymorphic Transition from $\alpha$-Form Shish Kebab to $\beta$-Form Highly Ordered Lamella under Intense Shear Field. Ind. Eng. Chem. Res. 2017, 56, 2764-2772. [CrossRef]

36. Hobeika, S.; Men, Y.; Strobl, G. Temperature and Strain Rate Independence of Critical Strains in Polyethylene and Poly(ethylene-co-vinyl acetate). Macromolecules 2000, 33, 1827-1833. [CrossRef]

37. Lu, Y.; Wang, Y.; Chen, R.; Men, Y. Crystallization and melting of isotactic polypropylene crystallized from quiescent melt and stress-induced localized melt. J. Polym. Sci. Part B Polym. Phys. 2017, 55, 957-963. [CrossRef]

38. Mao, Y.; Li, X.; Burger, C.; Hsiao, B.S.; Mehta, A.K.; Tsou, A.H. Structure Development during Stretching and Heating of Isotactic Propylene-1-Butylene Random Copolymer: From Unit Cells to Lamellae. Macromolecules 2012, 45, 7061-7071. [CrossRef]

39. Li, X.; Wu, H.; Huang, T.; Shi, Y.; Wang, Y.; Xiang, F.; Zhou, Z. $\beta / \alpha$ Transformation of $\beta$-polypropylene during tensile deformation: Effect of crystalline morphology. Colloid Polym. Sci. 2010, 288, 1539-1549. [CrossRef]

40. Yu, F.; Zhang, H.; Hong, Z.; Wei, Y.; Zhou, C. Modeling of flow-induced crystallization in blends of isotactic polypropylene and poly(ethylene-co-octene). Polym. Int. 2012, 61, 1389-1393. [CrossRef]

41. Coppola, S.; Grizzuti, N. Microrheological Modeling of Flow-Induced Crystallization. Macromolecules 2001, 34, 5030-5036. [CrossRef]

42. Wu, T.; Xiang, M.; Cao, Y.; Kang, J.; Yang, F. Influence of lamellar structure on the stress-strain behavior of $\beta$ nucleated polypropylene under tensile loading at elevated temperatures. RSC Adv. 2015, 5, 43496-43507. [CrossRef]

43. Mi, D.; Hong, L.; Lei, Z.; Tao, W.; Zhang, X.; Jie, Z. The Changes of Microstructure and Physical Properties of Isotactic Polypropylene/ $\beta$ Nucleation Agent/Polyolefin Elastomer Induced by Annealing Following Processing. J. Macromol. Sci. Part B 2015, 54, 1376-1390. [CrossRef]

44. Chen, Y.; Fang, D.; Hsiao, B.S.; Li, Z. Insight into unique deformation behavior of oriented isotactic polypropylene with branched shish-kebabs. Polymer 2015, 60, 274-283. [CrossRef]

45. Michler, G.H.; Balta, F.J. Mechanical Properties of Polymers Based on Nanostructure and Morphology; Taylor \& Francis Group: 2\&4 Park Square, Milton Park, Abingdon, UK, 2005; pp. 280-290.

46. Young, R.J.; Lovell, P.A. Introduction to Polymers, 3rd ed.; Taylor \& Francis Group: 2\&4 Park Square, Milton Park, Abingdon, UK, 2011; pp. 548-551.

(C) 2020 by the authors. Licensee MDPI, Basel, Switzerland. This article is an open access article distributed under the terms and conditions of the Creative Commons Attribution (CC BY) license (http://creativecommons.org/licenses/by/4.0/). 